\title{
Key recruitment and retention strategies for a pilot web-based intervention to decrease obesity risk among minority youth
}

Grisselle DeFrank ${ }^{1,2}$, Sarina Singh ${ }^{1}$, Katrina F. Mateo ${ }^{1,2}$, Laura Harrison ${ }^{1,2}$, Alyson Rosenthal $^{3}$, Allison Gorman ${ }^{4}$ and May May Leung ${ }^{1 *}$ (D)

\begin{abstract}
Background: Interactive Nutrition Comics for Urban Minority Youth (Intervention INC) is an innovative, web-based interactive comic tool for dietary self-management, which aims to decrease obesity risk among urban minority preadolescents. The feasibility and acceptability of Intervention INC was assessed by implementing a two-group randomized pilot study. To date, intervention studies have typically faced various barriers in recruiting and retaining study participants. The purpose of this paper is to describe recruitment and retention activities from this study and in particular, discuss challenges faced, strategies implemented, and lessons learned.
\end{abstract}

Methods: Black/AA and Latino children (ages 9-12 years) and their parent/guardian were recruited from East Harlem/Harlem, New York. Recruitment strategies included flyering in the community, having a convenient study location, providing participation incentives, and partnering with community/school-based organizations. Potential participants were screened for eligibility; enrollees completed online surveys and interviews at baseline (T1), intervention midpoint (T2), intervention end (T3), and 3-months post-intervention (T4). Retention strategies included flexible scheduling, reminder calls/texts, incremental compensation, and consistent study staff.

Results: Eighty-nine enrolled dyads completed a T1 visit (August to November 2017) and were randomized to the experimental $(E, n=45)$ or comparison $(C, n=44)$ group. Enrolled dyads learned about the study through community events (39\%), community flyering (34\%), friend/referral (15\%), or a community clinic partner (12\%). T1 child demographics were mean age $=10.4 \pm 1.0$ years, $61 \%$ female, $62 \%$ Black and $42 \%$ Latino, and $51 \%$ overweight/ obese; parent demographics were mean age $=30.8 \pm 8.9$ years, $94 \%$ female, and $55 \%$ Black and $45 \%$ Latino. Survey completion rates by dyad were high throughout the study: T2, 87\%; T3, 89\%; and T4, 84\%. Average data collection per session was $65 \mathrm{~min}$. Parents at T4 $(n=76)$ felt they received enough study information (97\%) and that their questions were answered properly (80\%). Eighty-one percent of children at T4 $(n=75)$ were very satisfied/extremely satisfied with how study staff communicated and interacted with them.

Conclusion: Effective recruitment strategies consisted of community events and flyering, while a variety of retention strategies were also used to successfully engage urban Black/AA and Latino families in this study. Though our findings are limited to only Latino and Black families in low-income neighborhoods, we have identified successful strategies for this specific high-risk population and potentially similar others.

(Continued on next page)

\footnotetext{
* Correspondence: maymay.leung@hunter.cuny.edu

${ }^{1}$ Hunter College School of Urban Public Health, City University of New York

(CUNY), 2180 Third Avenue, New York, NY 10035, USA

Full list of author information is available at the end of the article
}

(c) The Author(s). 2019 Open Access This article is distributed under the terms of the Creative Commons Attribution 4.0 International License (http://creativecommons.org/licenses/by/4.0/), which permits unrestricted use, distribution, and reproduction in any medium, provided you give appropriate credit to the original author(s) and the source, provide a link to the Creative Commons license, and indicate if changes were made. The Creative Commons Public Domain Dedication waiver (http://creativecommons.org/publicdomain/zero/1.0/) applies to the data made available in this article, unless otherwise stated. 
(Continued from previous page)

Trial registration: ClinicalTrials.gov, NCT03165474, registered 15 May 2017

Keywords: Childhood obesity, Research methods, Preadolescents, Trial, Community, Race/ethnicity, Recruitment, Retention, Pilot

\section{Background}

Childhood obesity is an ongoing public health crisis in the United States (US) that disproportionately affects low-income, minority individuals. A 2013 study showed that black and Hispanic children, compared with nonHispanic white children, have substantially higher body mass index (BMI) $z$-scores, total fat mass index, and prevalence of overweight and obesity [1]. Interventions delivered via web-based or mobile platforms (mHealth) that incorporate tailored and/or engaging health promotion content and utilize theory-driven strategies may help at-risk children and their parents improve their dietary-related practices to lower risk for childhood obesity and improve health outcomes. Importantly, however, rigorous evaluation of these interventions is needed to demonstrate their feasibility for delivery and adoption in real-world settings.

To date, intervention studies have typically faced numerous barriers in recruiting and retaining study participants, especially within at-risk populations. A well-documented challenge of minority recruitment is distrust of research, and especially clinical research [2-4]. Distrust stems from a history of discrimination as well as notorious research abuses, such as the US Public Health Service Tuskegee Syphilis Experiment [5]. Other participant barriers include lack of transportation, scheduling conflicts, recruitment materials at inappropriate literacy levels, and lengthy consent forms [6]. Further barriers on the part of researchers include a lack of understanding about cultural differences among ethnic minorities and subsequent poor communication with these groups at all research stages [6].

Recruiting and retaining minority children specifically for obesity-related interventions pose several additional challenges. A 2012 study by Wright et al. focused on the impact of a school health program on physical activity and BMI in minority children. The authors acknowledged that a major limitation of the study was retention, especially at 12-month follow-up [7]. Wright et al. suggested that a potential retention barrier was a lack of incentives, which could have inhibited parents who had to rush home after work to attend the program. In addition, child participation in studies requires significant family involvement, as parents, guardians, or caregivers must consent, provide support, and coordinate children's participation, actions, and responses. Any barriers to parents/guardians and families, therefore, can reduce successful child retention [8].
Another possible challenge to retaining minority children is maintaining their engagement throughout entire interventions [8]. It is therefore important for study staff to use creative tactics and planning strategies to ensure that children do not lose interest in the studies.

To date, few studies have attempted to analyze information about recruitment and retention in childhood obesity-related health interventions upon their completion [9, 10]. A 2015 systematic review by Cui et al., which analyzed recruitment and retention strategies of studies involving low-income, minority children, noted that one third of eligible studies had not a published peer-reviewed paper [8]. This highlights missed opportunities to report on the success or failure of recruitment and retention strategies used for minority children. In addition, well-documented rates of high attrition have led to limited interpretability and generalizability of study findings [11-13]. It is therefore important to identify key strategies that can lead to successful recruitment and high retention rates of minority children in intervention studies but also report on the implementation and impact on retention.

Therefore, the purpose of this paper is to describe recruitment and retention activities from the Interactive Nutrition Comics for Urban Minority Youth (Intervention INC) study (a 4.5-month pilot RCT), strategies implemented in response to challenges during study implementation, as well as discuss lessons learned and implications for similar intervention studies, particularly with minority youth.

\section{Methods}

Pilot study design

Intervention INC was a two-group randomized pilot study that assessed the usability, feasibility, and acceptability of an innovative, web-based interactive comic tool aimed at decreasing obesity risk among urban minority preadolescents. The study protocol and intervention are described briefly below, and in greater depth elsewhere [14].

Participants were recruited from low-income NYC neighborhoods from August to November 2017. Childparent dyads were eligible if the child was 9-12 years old at baseline, identified as either Black/AA or Latino, had a BMI percentile of $5 \%$ or higher, and was able to speak and read in English, and the parent was able to read and speak in either English or Spanish and was primarily 
responsible for providing or purchasing food for the child. Dyads also had to have regular internet access via a tablet device, smartphone, or computer/laptop with internet access. Both children and parents were compensated for time to complete questionnaires/interviews and travel to in-person study visits with gift cards (in increasing amounts for each data collection time point) and round-trip Metrocards. Parent consent and child assent were obtained prior to initiation of any study procedures.

For the intervention, children in the experimental group had access to a 6-chapter interactive nutrition comic (one chapter released a week), a goal-setting and self-assessment feature, and weekly text/email messages and reminders from comic characters, while children in the comparison group had access to six online newsletters with nutrition-related content, a goal-setting and self-assessment feature, and weekly text/email messages and reminders. Parents in both the experimental and comparison groups received six online newsletters with healthy feeding-related content and weekly text/email messages in reminders, but experimental group parents also had access to the child nutrition comic.

Dyads participated in the study for 4.5 months, which included a 6-week intervention and 3-month follow-up. Data collection occurred at four time points: baseline (T1), intervention midpoint or 3-weeks post-baseline (T2), intervention end or 6-weeks post-baseline (T3), and 3-month follow-up post-intervention (T4). T1 and $\mathrm{T} 4$ time points were in-person study visits, while $\mathrm{T} 2$ and $\mathrm{T} 3$ were conducted via phone and online. At $\mathrm{T} 1$, the child's height, weight, and body composition were measured. Both the child and parent then completed individual baseline questionnaires on laptop devices, which collected demographics and dietary-related outcome data. For the child, these data related to dietary knowledge, attitudes, and intake. For the parent, these data related to feeding practices and the home food environment [14]. Similar questionnaires were administered at T2 (child-only), T3 (child and parent), and T4 (child and parent). In addition to questionnaires, children and parents also completed semi-structured interviews to collect data about their experiences using the website at T2 (child-only), T3, and T4. At T4, children had their height, weight, and body composition taken again. Both the children and parents also completed additional questionnaire items related to the overall study participation experience.

\section{Recruitment protocol}

\section{Initial recruitment protocol}

Through a partnership with a child-focused communitybased organization (CBO) focused on serving at-risk youth in the East Harlem/Harlem neighborhoods of
NYC, study recruitment letters were sent to parents/ guardians of children who had utilized services from their community health clinic within the previous 2 years. Using basic child inclusion/exclusion criteria (age 9-12 years and BMI percentile above $85 \%$ ), a list of potential participants was generated, from the CBO's existing patient population, with the child's contact information. Bilingual recruitment letters signed by the CBO Medical Director, a CBO Pediatrician, and the study Principal Investigator were sent to the parents/ guardians of these children. The letters contained a brief description of the study, incentives, and contact information of study staff. Interested individuals had the option of calling, texting, or emailing study staff for additional information. These parents were also called by study staff approximately 1 week after letters were sent to assess interest in study participation. Study staff screened interested individuals and scheduled $\mathrm{T} 1$ visits. As participants were enrolled and scheduled for T1 visits, study staff sent reminder texts, calls, and emails (as preferred by participants) three days and one day prior to appointments.

\section{Changes to recruitment protocol}

Initial challenges with recruitment and enrollment led to the broadening of our recruitment approaches. Specifically, the BMI percentile criteria were changed from 85 to 5\% [14]. This BMI range includes healthy, overweight, and obese children. Following this change in inclusion criteria, updated potential participant lists from our $\mathrm{CBO}$ partner (i.e., with widened BMI percentile criteria to above 5\%) were created and additional recruitment letters were sent to families not included in the first round. Furthermore, our recruitment protocol was expanded to include flyering 3-5 days a week in East Harlem/Harlem neighborhoods. Study staff compiled a list of key recruitment outreach locations and conducted targeted flyering in these areas, which included churches, medical offices, housing complexes, schools, community organizations, and recreational spaces. To keep track of the areas covered, an interactive Google map was created and updated weekly by study staff. In addition to neighborhood flyering, we partnered with community organizations and local elementary/middle school schools that permitted study staff to table at their weekend/after-school events. At these events, study staff engaged youth in a fun, nutrition card game while providing parents with information about the study. Potential participants were screened in-person at the events to expedite enrollment.

\section{Data collection}

Once parents expressed interest in joining the study, study staff screened subjects for eligibility by assessing 
inclusion and exclusion criteria such as the following: Does your child read and speak English? Do you have access to an iPad, tablet, desktop, laptop, or phone with texting capabilities with internet access? Potential dyads received numerical IDs. Study staff monitored appointments via a Google Calendar accessible to all study staff using these IDs. At least 1 member of the study staff was responsible for monitoring each potential dyad and followed up with any potential dyad contact within 24 hours. If the parent was Spanish-speaking, a bilingual study staff member would be assigned to that dyad.

Study staff kept track of weekly recruitment/enrollment status, all communications with dyads, and number of dyads enrolled per week. Specifically for every dyad, the following information was collected during recruitment: who made first contact (participant or study staff), mode of contact, date of first contact, study staff that communicated with participant, number of contact points until scheduled, how they learned about the study, race, ethnicity, and age of child. In addition, study staff held weekly meetings to discuss these outcomes and develop improvement strategies as challenges surfaced. We anticipated to recruit 82 study dyads over the course of 3 months.

During T1, dyads completed demographic surveys in person at the Hunter College campus located in East Harlem. Surveys were administered as a questionnaire through a laptop computer in a private room with parent, child, and 2 research study staff. Participants were told that they should complete the surveys individually and study staff were available to assist. Challenges were systematically documented and discussed during weekly research team meetings, and strategies were implemented to address any challenges.

\section{Retention protocol}

Study staff offered flexible scheduling 7 days a week, which included after-school and work hours. At the end of each T1 visit, study staff documented expected follow-up dates for the midpoint, endpoint, and 3-month follow-up visits for the participants. As each time point approached, the date and time of the following visit or follow-up were confirmed and/or adjusted, and updated on the Google calendar. Once appointments were confirmed, study staff conducted 3-day and same-day reminder calls or texts; and a 1-day confirmation text or call. Visit outcomes were labeled as completed, rescheduled, or no-show. If dyads were $10 \mathrm{~min}$ late to their appointment, they were contacted by study staff. After 30 min, dyads were considered "no-shows" and study staff immediately reached out to request a reschedule.

To maintain dyad comfort and consistency with the research project, one study staff was assigned to each dyad so that the dyad interacted with the same study staff member through the study period and at each time point. Dyads were also sent newsletters and recipes between T3 and T4 to encourage continued engagement in the study. Thank you cards were sent at T3 with compensation for completing T3, a reminder of the upcoming appointment in 3 months, and appreciation of continued participation.

\section{Incentives}

Participants were compensated with round-trip MetroCards for in-person data collection and gift cards of their choice for each time point. Gift card options included the following: large department store, supermarket chain specializing in selling organic products, discount supermarket chain, and sporting goods store. Selection of these gift cards was informed by formative research asking parents and input from a communitybased organization (not published). Gift card monetary value increased at each time point: at $\mathrm{T} 1$, children received $\$ 10$ gift cards and parents received $\$ 15$ gift cards; at T2, children received $\$ 15$ gift cards; at T3, both children and parents received $\$ 15$ gift cards; at T4, children received $\$ 25$ gift cards and parents received $\$ 30$ gift cards. Participants were also informed that upon completion of all time points, they would be entered into a raffle to win a $\$ 100$ gift card. To enhance the study experience, participants were provided healthy snacks and beverages (tea, coffee, water) at any in-person study visits.

\section{Data collection}

Study staff logged completion dates of each time point, durations of various measures (e.g., time taken to complete surveys), notes on dyad communication, dyad status, and retention percentages on a shared spreadsheet. In addition, barriers to website access (e.g., technological, password, and scheduling) and any comments about the study that participants communicated to study staff (not as part of data collection) were noted in the shared spreadsheet. Dyads were considered lostto-follow-up if they did not respond to all attempted methods of communication from study staff including text, email, phone call, and mail within 2 weeks after their scheduled T2 or T3 visit or within 4 weeks after their scheduled T4 visit. A dyad was considered to have completed a time point if: both parent and child completed surveys at T1, T3, and T4. This information was organized into a shared spreadsheet that was regularly updated and reviewed at study staff meetings. Strategies for retention were reviewed and amended as needed.

At T4, children and parents individually completed study experience surveys. All questions were asked on a Likert scale from 1 (not satisfied) to 4 (extremely satisfied). Questions for guardians included the following: 
How satisfied were you with your experience in this study? Did we give you enough information about the study? How easy was it to get in touch with us if you had a question? Questions for children included the following: How satisfied were you with your experience in this study? How satisfied were you with how we communicated and interacted with you?

\section{Data analysis}

Data was analyzed using IBM SPSS Statistics for Windows, Version 22.0. Armonk, NY: IBM Corp. Descriptive statistics were run for all demographic variables for enrolled participants. Chi-square tests were used to compare demographics of experimental and comparison arm participants, with a significance level of $p=0.05$. Retention data were analyzed using binary logistic regression to assess characteristics of participants who completed each data collection point compared to those who did not.

Study protocols and detailed study notes documented by study staff were systematically reviewed to identify significant changes, adjustments, or barriers to implementing the original protocol. Implementation of key recruitment and retention strategies that were documented throughout study implementation were also systematically reviewed with team members and reflected upon.

\section{Results}

\section{Recruitment}

Recruitment occurred between August 2017 and November 2017. Key recruitment strategies implemented included flyering, partnering with a community clinic, and attending community events. Table 1 shows recruitment activities by month.

\section{Enrollment by activity}

Figure 1 shows the total number of hours spent on recruitment per week (triangular points), the number of hours spent on each recruitment activity per week (circular points), the number of dyads enrolled per week (diamond points) as a cumulative number (triangular points). Study staff spent 514 total hours recruiting 89 dyads. Overall, weekly staff hours increased from the week of August 14th $(35.33 \mathrm{~h})$ to the week of November 6th $(56.25 \mathrm{~h})$. Number of dyads enrolled weekly also increased from August 14th (0 dyads) to November 6th (16 dyads). In addition, the rate of dyads enrolled increased after September 11th and again after October 23rd. Weekly communication hours (texting, calling, emailing, and mailed letters) declined from the week of August 28th $(17.5 \mathrm{~h})$ to the week of September 11th $(5.17 \mathrm{~h})$ but had an overall increase from the week of September 11th $(5.17 \mathrm{~h})$ to the week of November 6 th $(43.25 \mathrm{~h})$. From the week of October 23rd to the week of October 30th, there was a large increase in event tabling hours as well as number of dyads enrolled. Weekly flyering hours fluctuated considerably for the duration of recruitment.

\section{Participant enrollment details}

The CONSORT diagram in Fig. 2 shows the progress of study recruitment. One hundred and seventy-five people (adults) were initially screened for eligibility, and of these, 47 declined to participate and 39 did not meet the inclusion criteria due to (categories not mutually exclusive) age (20); race/ethnicity (7); medical condition, e.g., heart condition; reading or learning disability (21); attendance issues (12); and access to technology (5). Of the 89 participants that were enrolled in the study, 30 learned about the study through flyering, 11 through the partner community clinic (includes cold calling and letters), 35 through community events that were staffed by trained study staff, and 13 through a friend/referral. One hundred and thirty-three parent-child dyads were scheduled for a baseline appointment, 89 dyads completed a baseline visit, and were randomized. The last participant was enrolled on November 11, 2017, for a total recruitment period of 4 months.

Table 1 Intervention INC recruitment activities by month

\begin{tabular}{ll}
\hline Month & Activities \\
\hline August & - Mailed recruitment letters to individuals that met initial inclusion criteria \\
& - Posted flyers in 25-block radii in East Harlem \\
- Participated in first community event (a "back to school"-themed celebration) where children and \\
parents played nutrition games and received information about the study \\
- Sent reminders for T2 appointments via texts and phone calls \\
- Handed out flyers at large shopping complexes, local businesses, and other areas with high foot traffic \\
- Participated in fall- and school-themed events where information about the study was provided \\
- Sent reminders for T3 appointments via texts and phone calls \\
- Re-posted flyers in 25 -block radii in East Harlem \\
- Participated in community events at new locations such as food-access organizations and local \\
October \\
elementary schools; they also began to screen potential participants at community events to expedite enrollment \\
- Mailed second batch of recruitment letters to potential participants \\
- Provided flyers to churches
\end{tabular}




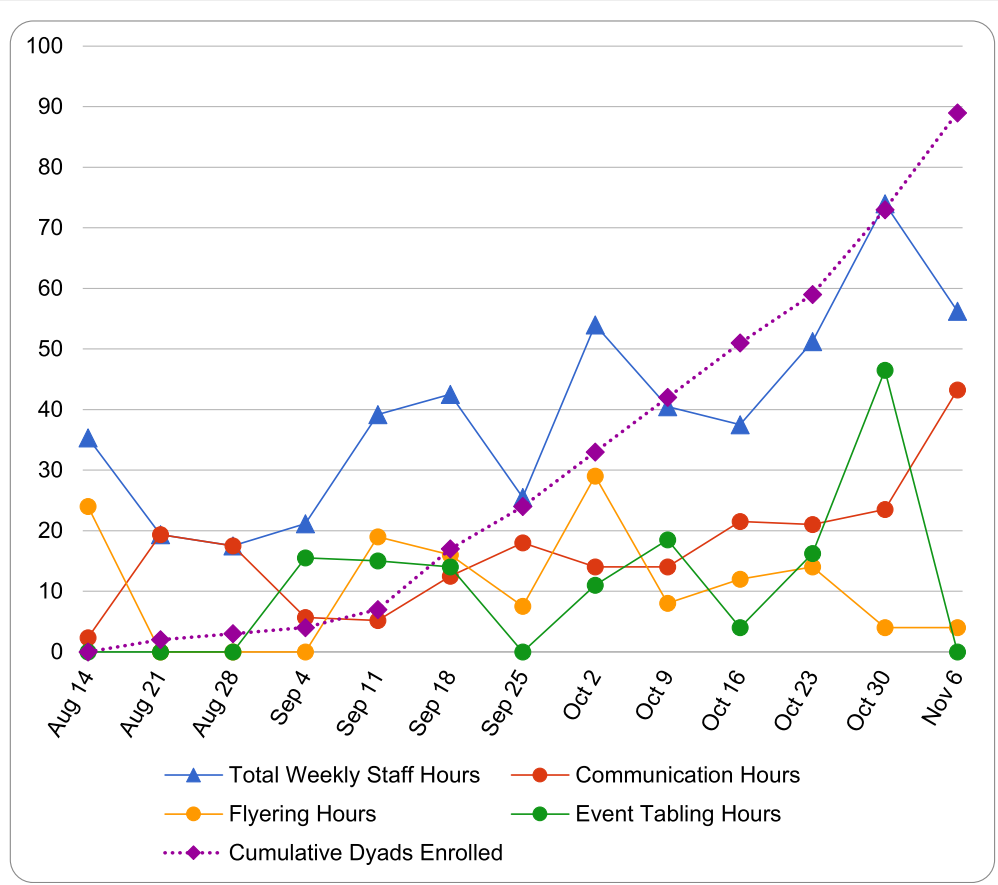

Fig. 1 Intervention INC recruitment activity hours and dyads enrolled

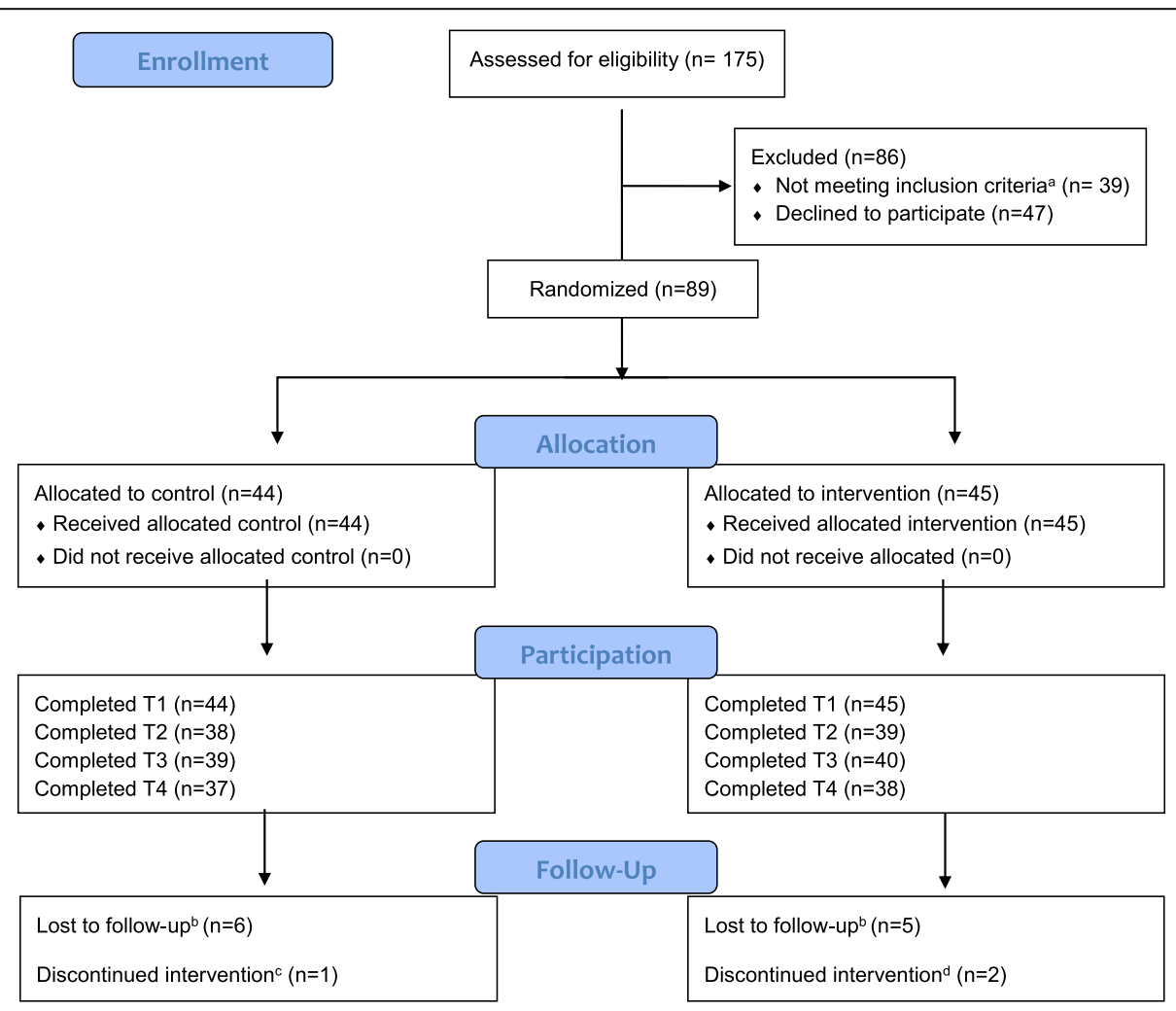

Fig. 2 CONSORT diagram: intervention INC pilot study. a Did not meet study criteria due to heart condition, BMI, parent did not speak Spanish or English, did not have internet access, race/ethnicity reading problem, attendance and/or, age. b No response to communication attempts including calls, emails, texts or mailings. c Parent was unable to continue study due to medical reasons. d Child did not want to continue participating in the study 


\section{Baseline characteristics of enrolled participants}

A total of 89 parent-child dyads were recruited into the study. Table 2 shows the characteristics of the adult and child participants enrolled into the study. The demographic breakdown of the adults enrolled are mean age $30.8 \pm 8.9$ years; $94.4 \%$ female; $3.4 \%$ White/Caucasian, 50.6\% Black/African American, and 39.3\% Hispanic/ Latino; $73 \%$ U.S. born; $20.5 \%$ less than high school; and $60.2 \%$ of adult participants participated in SNAP. The demographic breakdown of the children enrolled are mean age $10.4 \pm 1.0$ years, $59.3 \%$ female, $46.2 \%$ Black/African American and 29.7\% Hispanic/Latino, and $97.8 \%$ U.S. born.

\section{Recruitment strategies and challenges}

Table 3 summarizes the recruitment strategies implemented, what challenges were encountered, and what solutions were devised. Recruitment strategies included partnering with community clinics, contacting eligible potential participants with trained study staff, recruiting over the summer, flyering in targeted areas of Harlem, providing a convenient study location, monetary incentives, maintaining a unified communication system (using a single phone number and simplified email address for the study), and having ongoing quality improvement processes. Challenges with our recruitment strategies included inaccurate self-reported height and weight measurements, BMI in electronic record not current, difficulty reaching potential participants (due to outdated contact information from community clinic lists), frequent no-shows and cancelations of baseline visits, and flyers were frequently torn down. Through ongoing quality improvement processes, we implemented several solutions which included the following: conducted additional community outreach (tabling at community events and clinics), partnered with community programs and institutions, expanded the eligibility criteria, utilized snowball recruitment, extended recruitment period into the fall (took advantage of back-to-school events), enhanced communication (texting more frequently, appointment reminders), and increased time spent on flyering.

\section{Retention}

\section{Study implementation}

Eighty-nine dyads completed all data collection activities at T1. Table 4 shows the duration of selected data collection activities. The average length of time that it took a dyad to complete an in-person session was 65 min, $73.5 \mathrm{~min}$ for a child to complete a phone interview, and $74 \mathrm{~min}$ for a parent to complete a phone interview.

\section{Participant retention}

Eighty-nine (100\%) dyads completed surveys at T1, 77 (86.5\%) dyads at T2, 79 (88.8\%) dyads at T3, and 75
(84.3\%) dyads at T4. No statistically significant differences in completion among gender, race/ethnicity, group allocation, age, BMI category (child-only), household income.

\section{Retention strategies and challenges}

Table 5 summarizes the retention strategies used during the study, what challenges were encountered and what solutions were made. Retention strategies included assigning one study member staff to a dyad for the length of the study, incremental monetary incentives, providing a family-friendly experience (such as accommodating other family members during in-person study sessions and providing toys for younger siblings), flexible scheduling (evening and weekends), maintaining a unified communication system (using a single phone number and simplified email address for the study), and having ongoing quality improvement processes. Challenges with our retention strategies involved issues with mailing gift cards to participants, unplanned participants' guests attending study visits, and participant issues with technology use. Through ongoing quality improvement processes, we implemented several solutions: providing availability for participants to pick up gift cards at the study site, accommodating study participants' guests, and offering technical assistance over the phone or inperson with trained study staff.

\section{Gift cards}

Across all time points, most children selected the large department store $(79.8 \%)$, followed by the sporting goods store (15.3\%), the supermarket chain specializing in selling organic products $(4.7 \%)$, and the discount supermarket chain (0.3\%). Parents selected gift cards for T1, T3, and T4 and across these time points most parents selected the large department store (73.1\%), followed by the supermarket chain specializing in selling organic products $(13.5 \%)$, the discount supermarket chain $(7.8 \%)$, and the sporting goods store (5.7\%).

\section{Study experience}

Seventy-six adults and 75 child participants completed the online study experience survey at T4. Of the 76 adults that completed the survey, $97.4 \%$ felt that they received enough information about the study, 98.4\% felt that study staff answered their questions properly, and $97.4 \%$ felt that study staff were flexible in scheduling your interview calls and visits. Of the 75 child participants that completed the survey, $68 \%$ were very satisfied/satisfied with their experience in the study. Additionally, 81.4\% were extremely satisfied/satisfied with how study staff communicated and interacted with them. There are no statistically significant differences in the study experience 
Table 2 Demographic characteristics of Intervention INC participants

\begin{tabular}{|c|c|c|c|}
\hline & $\begin{array}{l}\text { Overall } \\
N(\%)\end{array}$ & $\begin{array}{l}\text { Experimental } \\
N(\%)\end{array}$ & $\begin{array}{l}\text { Comparison } \\
N(\%)\end{array}$ \\
\hline \multicolumn{4}{|l|}{ Parent } \\
\hline \multicolumn{4}{|l|}{ Age } \\
\hline$<35$ & $28(31.5)$ & $15(33.3)$ & $13(29.5)$ \\
\hline $36-45$ & $37(41.6)$ & $19(42.2)$ & $18(40.9)$ \\
\hline $46-55$ & 21 (23.6) & $10(22.2)$ & $11(25.0)$ \\
\hline $55+$ & $3(3.4)$ & $1(2.2)$ & $2(4.5)$ \\
\hline \multicolumn{4}{|l|}{ Gender } \\
\hline Male & $5(5.6)$ & $2(4.4)$ & $3(6.8)$ \\
\hline Female & $84(94.4)$ & $43(95.6)$ & $41(93.2)$ \\
\hline \multicolumn{4}{|l|}{ Race/ethnicity } \\
\hline White/Caucasian & $3(3.4)$ & $1(2.2)$ & $2(4.5)$ \\
\hline Black/African American & $45(50.6)$ & $21(46.7)$ & $24(54.5)$ \\
\hline Hispanic/Latino & $35(39.3)$ & $18(40.0)$ & $17(38.6)$ \\
\hline Multiracial/other & $6(6.7)$ & $5(11.4)$ & $1(2.3)$ \\
\hline \multicolumn{4}{|l|}{ Household income** } \\
\hline$<\$ 20,000$ & $29(32.6)$ & $15(33.3)$ & $14(32.6)$ \\
\hline$\$ 20,000-\$ 39,999$ & $30(33.7)$ & $17(37.8)$ & $13(30.2)$ \\
\hline$\$ 40,000-\$ 59,999$ & $18(20.2)$ & $9(20.0)$ & $9(20.9)$ \\
\hline$\$ 60,000$ or more & $11(12.4)$ & $4(8.9)$ & $7(16.3)$ \\
\hline \multicolumn{4}{|l|}{ Country of birth } \\
\hline USA & $65(73.0)$ & $32(71.1)$ & $33(75.0)$ \\
\hline Foreign born & $24(27.0)$ & $13(28.9)$ & $12(27.3)$ \\
\hline \multicolumn{4}{|l|}{ Highest level of education** } \\
\hline $\begin{array}{l}\text { Less than HS/finished } \\
\text { HS/GED }\end{array}$ & $28(31.8)$ & $17(37.8)$ & $11(25.6)$ \\
\hline $\begin{array}{l}\text { Some college/finished } \\
\text { college }\end{array}$ & $52(59.1)$ & $24(53.3)$ & $28(65.1)$ \\
\hline Other & $8(9.1)$ & $4(8.9)$ & $4(9.3)$ \\
\hline \multicolumn{4}{|l|}{ Marital status** } \\
\hline Single & $40(45.5)$ & $23(51.1)$ & $17(39.5)$ \\
\hline $\begin{array}{l}\text { Married/in marriage-like } \\
\text { relationship }\end{array}$ & $34(38.6)$ & $16(35.6)$ & $18(41.9)$ \\
\hline $\begin{array}{l}\text { Separated/divorced/ } \\
\text { widowed }\end{array}$ & $14(15.9)$ & $6(13.3)$ & $8(18.6)$ \\
\hline \multicolumn{4}{|l|}{ Relationship to child** } \\
\hline Mother/stepmother & 78 (88.6) & $42(93.3)$ & $36(83.7)$ \\
\hline Father/stepfather & $4(4.5)$ & $1(2.2)$ & $3(7.0)$ \\
\hline Grandmother & $4(4.5)$ & $1(2.2)$ & $3(7.0)$ \\
\hline Other & $2(2.3)$ & $1(2.2)$ & $1(2.3)$ \\
\hline \multicolumn{4}{|l|}{ SNAP participation** } \\
\hline Yes & $53(60.2)$ & $27(60.0)$ & $26(60.5)$ \\
\hline No & 35 (39.8) & $18(40.0)$ & $17(39.5)$ \\
\hline I don't & & & \\
\hline
\end{tabular}

Table 2 Demographic characteristics of Intervention INC participants (Continued)

\begin{tabular}{|c|c|c|c|}
\hline & $\begin{array}{l}\text { Overall } \\
N(\%)\end{array}$ & $\begin{array}{l}\text { Experimental } \\
N(\%)\end{array}$ & $\begin{array}{l}\text { Comparison } \\
N(\%)\end{array}$ \\
\hline \multicolumn{4}{|l|}{ Child } \\
\hline \multicolumn{4}{|l|}{ Age } \\
\hline 9-9.99 years & $23(25.8)$ & $11(24.4)$ & $12(27.3)$ \\
\hline 10-10.99 years & $22(24.7)$ & $12(26.7)$ & $10(22.7)$ \\
\hline $11-11.99$ years & $31(34.8)$ & 16 (35.6) & $15(34.1)$ \\
\hline $12-12.999$ years & $13(14.6)$ & $6(13.3)$ & $7(15.9)$ \\
\hline \multicolumn{4}{|l|}{ BMI class } \\
\hline Normal & $42(47.2)$ & $21(46.7)$ & $21(47.7)$ \\
\hline Overweight & $19(21.3)$ & $9(20.0)$ & $10(22.7)$ \\
\hline Obese & $28(31.5)$ & $15(33.3)$ & $13(29.5)$ \\
\hline \multicolumn{4}{|l|}{ Gender } \\
\hline Male & 35 (39.3) & $17(37.8)$ & $18(40.9)$ \\
\hline Female & $54(60.7)$ & $28(62.2)$ & $26(59.1)$ \\
\hline \multicolumn{4}{|l|}{ Race/ethnicity*** } \\
\hline Black only & $42(47.2)$ & $20(44.4)$ & $22(50.0)$ \\
\hline Hispanic only & $29(32.6)$ & $15(33.3)$ & $14(31.8)$ \\
\hline Black and Hispanic & $8(9.0)$ & $6(13.3)$ & $2(4.5)$ \\
\hline Mixed_Black & $6(6.7)$ & $3(6.7)$ & $3(6.8)$ \\
\hline Mixed_Hispanic & $4(4.5)$ & $1(2.2)$ & $3(6.8)$ \\
\hline \multicolumn{4}{|l|}{ Country of birth } \\
\hline USA & $87(97.8)$ & $43(95.6)$ & $44(100.0)$ \\
\hline Foreign born & $1(1.1)$ & $1(2.2)$ & $0(0.0)$ \\
\hline Did not know & $1(1.1)$ & $1(2.2)$ & $0(0.0)$ \\
\hline
\end{tabular}

${ }^{*}$ No significant differences were found between Experimental and Comparison for demographic characteristics

**One participant did not answer the survey question

***Race/ethnicity not mutually exclusive

responses between the experimental arm and the comparison arm for both adult and child participants.

\section{Discussion}

Recruitment and retention of study participants, especially from low-income, minority populations, has historically been a significant challenge $[15,16]$. Few studies, furthermore, provide reliable data on recruitment and retention of low-income, minority children [6]. Intervention INC successfully recruited 89 parentchild dyads over the course of 4 months and retained $84.3 \%$ of dyads during its 4.5 -month study using a variety of strategies.

\section{Recruitment}

In this study, the use of multiple recruitment strategies and continuous assessment of and adjustment to recruitment needs increased the rate of enrollment over time. In the early phase of recruitment (August 2017), recruitment 
Table 3 Intervention INC recruitment strategies and results

\begin{tabular}{|c|c|c|}
\hline Strategy & Challenge(s) & Solution(s) \\
\hline $\begin{array}{l}\text { Obtained lists of eligible patients } \\
\text { - Built upon existing partnerships with } \\
\text { community clinics to obtain potential study } \\
\text { participants } \\
\text { - Partnered with FQHC to obtain potential } \\
\text { study participants }\end{array}$ & $\begin{array}{l}\text { - Difficulty receiving approvals to obtain lists in } \\
\text { secure way } \\
\text { - Difficulty creating broad enough eligibility } \\
\text { criteria to identify patients } \\
\text { - Difficulty with accurate databases to identify } \\
\text { patients } \\
\text { - Unable to obtain patient list from FQHC in } \\
\text { timely manner due to privacy concerns }\end{array}$ & $\begin{array}{l}\text { - Additional community outreach-tabled at } \\
\text { community events, school events, and } \\
\text { community clinics locations } \\
\text { - Provided nutritional education } \\
\text { - Provided food samples } \\
\text { - Partnered with community programs and } \\
\text { institutions-elementary/junior high schools, } \\
\text { public parks, YMCA }\end{array}$ \\
\hline $\begin{array}{l}\text { Contacted eligible patients with trained study } \\
\text { staff (including bilingual study staff) } \\
\text { - Sent letters with study information to } \\
\text { potential participants from patient lists } \\
\text { (selected based on BMI measure from last } \\
\text { medical visit) and co-signed by clinic } \\
\text { physician } \\
\text { - Cold called from patient lists }\end{array}$ & $\begin{array}{l}\text { - Difficulty in reaching potential participants } \\
\text { from community clinic lists due to outdated } \\
\text { contact information } \\
\text { - Unable to recruit participants within target } \\
\text { time frames } \\
\text { - Frequent no-shows and cancelations of } \\
\text { baseline visits } \\
\text { - Parents provided inaccurate estimates of child's } \\
\text { height and weight } \\
\text { - Difficulty recruiting children in overweight/ } \\
\text { obese BMI percentile categories }\end{array}$ & $\begin{array}{l}\text { - Expanded BMI eligibility criteria } \\
\text { - Conducted snowball recruitment-sought } \\
\text { referrals from parental participants } \\
\text { - Extended recruitment period } \\
\text { - Required potential participants' verbal } \\
\text { confirmation for 1- and 3-day confirmation } \\
\text { - Enhanced communication, i.e., texting more } \\
\text { frequently }\end{array}$ \\
\hline $\begin{array}{l}\text { - Provided a family-friendly experience } \\
\text { - Positive interactions with study staff }\end{array}$ & $\begin{array}{l}\text { - Additional children and family members } \\
\text { attended study visits } \\
\text { - Not enough snacks for additional people } \\
\text { - Initially, no methods of entertaining/distracting } \\
\text { additional kids } \\
\text { - Additional people in the room distracted } \\
\text { parents/kids during data collection }\end{array}$ & $\begin{array}{l}\text { - Provided entertainment for other siblings, i.e., } \\
\text { toys, drawing } \\
\text { - Provided access to wifi (to use on personal } \\
\text { devices) for older siblings/other adults } \\
\text { - Ensured availability of larger meeting space or } \\
\text { multiple spaces if multiple people came } \\
\text { - Bought additional supplies }\end{array}$ \\
\hline $\begin{array}{l}\text { - Recruited in the summer when families have } \\
\text { more time }\end{array}$ & - Slow recruitment & $\begin{array}{l}\text { - Extended recruitment into the fall and took } \\
\text { advantage of back-to-school events and fall } \\
\text { festivals } \\
\text { - Extended available times for data collection } \\
\text { sections to include after-school hours and } \\
\text { evenings }\end{array}$ \\
\hline $\begin{array}{l}\text { - Flyered in targeted areas of Harlem (included } \\
\text { bilingual study staff, always in pairs) }\end{array}$ & $\begin{array}{l}\text { - Community push-back } \\
\text { - Flyers frequently torn down }\end{array}$ & $\begin{array}{l}\text { - Increased time spent on community flyering/ } \\
\text { increase number of flyers posted } \\
\text { - More strategic flyering (e.g., posted in local } \\
\text { businesses with their approval, distributed } \\
\text { flyers to interested local organizations such as } \\
\text { churches, clinics) }\end{array}$ \\
\hline $\begin{array}{l}\text { - Convenient study location centrally located in } \\
\text { East Harlem neighborhood and flexible study } \\
\text { visit dates/times (included weekends and } \\
\text { evenings) }\end{array}$ & $\begin{array}{l}\text { - Unanticipated issues with allowing study } \\
\text { participants to enter building (with security) }\end{array}$ & $\begin{array}{l}\text { - Enhanced communication with building } \\
\text { security } \\
\text { - Requested parents to text us directly upon } \\
\text { arrival and did not rely on security to call } \\
\text { study staff }\end{array}$ \\
\hline \multicolumn{3}{|l|}{$\begin{array}{l}\text { Incentives } \\
\text { - Up to } \$ 70 \text { in gift cards for the parents/ } \\
\text { guardians for completing study visit } \\
\text { - Up to } \$ 65 \text { in gift cards for children } \\
\text { completing study visits } \\
\text { - } \$ 100 \text { gift card raffle entry for dyad } \\
\text { participants that completed all study } \\
\text { components } \\
\text { - Variety of gift cards to choose from: Aldi, } \\
\text { Wholefoods, Modell's, Target }\end{array}$} \\
\hline $\begin{array}{l}\text { Unified communication system } \\
\text { - Used Google Voice number as single study } \\
\text { phone and texting line } \\
\text { - Single Hunter College email address } \\
\text { accessible to all study staff } \\
\text { - Used Google calendar as central scheduling } \\
\text { platform }\end{array}$ & $\begin{array}{l}\text { - Coordinated monitoring of the study line and } \\
\text { email (especially with Spanish-speaking } \\
\text { participants) } \\
\text { - Coordinated availability of study staff to } \\
\text { moderate study visit (originally the person who } \\
\text { made contact would also be moderator, but } \\
\text { changed to whoever was available to } \\
\text { moderator session) }\end{array}$ & $\begin{array}{l}\text { - Additional staff (especially Spanish-speaking) } \\
\text { added to the study team } \\
\text { - Standardized monitoring/scheduling } \\
\text { procedure was incorporated }\end{array}$ \\
\hline
\end{tabular}


Table 4 Duration in minutes of Intervention Inc data collection activities

\begin{tabular}{lllll}
\hline & & $n$ & Mean (SD) & Range \\
\hline T1 & Overall & 89 & $69(14)$ & $39-119$ \\
& Child survey & 89 & $25(7)$ & $4-46$ \\
& Parent survey & 89 & $12(6)$ & $4-38$ \\
T2** & Child interview & 73 & $16(5)$ & $6-40$ \\
T3** $^{*}$ & Child interview & 74 & $16(6)$ & $4-37$ \\
& Parent interview & 74 & $18(8)$ & $3-58$ \\
T4 & Overall & 72 & $61(13)$ & $39-101$ \\
& Child survey & 75 & $19(8)$ & $4-40$ \\
& Parent survey & 76 & $10(6)$ & $3-32$ \\
& Interview & 76 & $19(6)$ & $6-33$ \\
\hline
\end{tabular}

*Independent sample $t$ tests were run and there were no significant differences incompletion times between Experimental and Comparison arms **Survey time not available because they were not completed in person

strategies were largely limited to mailing letters and calling individuals identified by the $\mathrm{CBO}$ health clinic, and random flyering in the East Harlem community. Dyad enrollment was relatively low during this month and thus required a re-assessment and adjustment of approaches used. Coinciding with back-to-school and Fall community and school events, additional recruitment activities were implemented, such as attending and tabling at large-attendee school/community events. Additionally, targeted flyering was done near local businesses and through partnerships with community organizations, and event tabling was utilized. Consequently, the rate of dyad enrollment was faster from September to October 2017.

Interestingly, despite having access to potential participant list of children that had used the services of a CBO health clinic within the last 2 years and sending recruitment letters signed by the CBO Medical Director, a CBO Pediatrician, and the study Principal Investigator, few participants were enrolled using this approach. Only $12.4 \%$ of enrolled participants learned about the study through community clinic partnerships, which included the $\mathrm{CBO}$ potential participant lists. By comparison, the most successful recruitment strategies included community flyering and attending community events as $33.7 \%$ and $39.3 \%$, respectively, of our study participants were enrolled by these strategies.

Aligned with the recruitment experiences in this study, Hartlieb et al. found in their study of recruiting minority adolescents with obesity that the use of multiple recruitment strategies-including identifying eligible participants through clinical partnerships, flyering within the community, and participating in health fairs-is beneficial and can yield high retention [11]. The decision to enhance community-based recruitment may have accelerated enrollment since individual choices are often dependent upon strong community ties [6].
Community-based recruitment of minority participants also likely creates trust and more positive relationships with study staff [17]. Indeed in other literature, recruitment of low-income, minority populations have most often included methods such as advertisements, targeted mailing and calls using organization lists, neighborhood canvassing, and community and health fair presentations [18].

It should be noted that our ability to continuously assess and modify strategies may have been, in large part, key to our recruitment success. At weekly team meetings, we were able to evaluate the data and therefore quickly implement new strategies as needed. For example, upon realizing that the BMI percentile criteria was too limited, we subsequently modified it to be more inclusive. Additionally, our staff members were flexible and allowed participants to schedule baseline appointments on weekends and during late hours. Staff members were also able to accommodate a longer recruitment period that had been extended for an additional 2 months.

Similar to our experiences with accommodation and adaptability in recruitment, Warner et al. found in their study that consistent evaluation of recruitment data to create new strategies followed by quick implementation was largely attributed to their success in participant enrollment [19]. Furthermore, their study staff's willingness to meet participant needs and general flexibility were factors also associated with successful recruitment [19]. Offering more flexible hours helps to meet the needs of individual participants; this is especially important for low-income, minority parents who are not able to compromise their work schedule in order to be part of the intervention [20].

\section{Retention}

Retention remained high throughout the study with completion of $\mathrm{T} 4$ at $84.3 \%$. No statistically significant difference was found with retention among the different demographic groupings (race/ethnicity, income, BMI category, gender, and age). These findings are in line with a similar 9-month study among racial/ethnic minority family dyads that reported $88 \%$ retention [17]. Parent and child participants reported high satisfaction rates at the end of our study. This may indicate that our retention strategies were successful in retaining Black and Latino families in East Harlem regardless of subgroups. It took participants an average of $69 \mathrm{~min} /$ time point to complete data collection study activities over a period of 4.5 months. The amount of time that participants commit to the research study has been one of the components used by other studies to measure participant burden [21, 22], We did not measure burden in this study, thus cannot discern if the amount of time that participants spent on 
Table $\mathbf{5}$ Intervention INC retention strategies and results

\begin{tabular}{|c|c|c|}
\hline Strategy & Challenge(s) & Solution(s) \\
\hline $\begin{array}{l}\text { - Assigned trained study staff to dyads at baseline } \\
\text { visit for the length of the study }\end{array}$ & $\begin{array}{l}\text { - Study staff left while the study was still in } \\
\text { progress }\end{array}$ & $\begin{array}{l}\text { - Study staff that were leaving gave notice } \\
\text { to PI } \\
\text { - Reassigned dyads to available trained } \\
\text { study staff }\end{array}$ \\
\hline $\begin{array}{l}\text { Incentives } \\
\text { - Up to } \$ 70 \text { in gift cards for the parents/guardians } \\
\text { for completing study visit. Amount increased for } \\
\text { each study visit } \\
\text { - Up to } \$ 65 \text { in gift cards for children completing } \\
\text { study visits. Amount increased for each study } \\
\text { visit. } \\
\text { - } \$ 100 \text { gift card raffle entry for dyad participants } \\
\text { that completed all study components. } \\
\text { - Variety of gift cards to choose from: Aldi, } \\
\text { Wholefoods, Modell's, Target } \\
\text { o Based on previous research }\end{array}$ & $\begin{array}{l}\text { Mailing gift cards } \\
\text { - Due to mailbox issues, some participants did } \\
\text { not receive gift cards }\end{array}$ & $\begin{array}{l}\text { - Participants that were unable to receive } \\
\text { mail picked up gift cards at the study site }\end{array}$ \\
\hline $\begin{array}{l}\text { Family-friendly experience and interactions with } \\
\text { study staff } \\
\text { • No explicit rule around bringing additional family } \\
\text { members to study visit }\end{array}$ & $\begin{array}{l}\text { - Additional children/members attended study } \\
\text { visits } \\
\text { - Initially, not enough snacks for additional } \\
\text { people } \\
\text { - Initially, no methods of entertaining additional } \\
\text { kids } \\
\text { - Having additional people in the room } \\
\text { distracted parents/kids during data collection }\end{array}$ & $\begin{array}{l}\text { - Provided entertainment for other siblings, } \\
\text { i.e., toys, drawing } \\
\text { - Provided access to wifi (to use on personal } \\
\text { devices) for older siblings/other adults } \\
\text { - Ensured availability of larger meeting } \\
\text { space or multiple spaces if multiple people } \\
\text { came }\end{array}$ \\
\hline $\begin{array}{l}\text { Flexible options for completing second and third } \\
\text { study visits } \\
\text { - Telephone } \\
\text { - Video calling }\end{array}$ & $\begin{array}{l}\text { - Some adult participants were unable to } \\
\text { complete questionnaires on their own because } \\
\text { they were not comfortable using technology }\end{array}$ & $\begin{array}{l}\text { - Participants were offered the option to } \\
\text { come in person and meet with trained } \\
\text { study staff to complete the questionnaire } \\
\text { - Participants were offered assistance } \\
\text { completing the questionnaire through the } \\
\text { phone }\end{array}$ \\
\hline \multicolumn{3}{|l|}{$\begin{array}{l}\text { Provided a hospitality room and were greeted by } \\
\text { trained study staff } \\
\text { - Toys } \\
\text { - Food and beverages } \\
\text { - Seating area }\end{array}$} \\
\hline \multicolumn{3}{|l|}{$\begin{array}{l}\text { Internal communication and ongoing quality } \\
\text { improvement } \\
\text { - Weekly meeting to discuss challenges } \\
\text { - Trained in providing excellent customer services } \\
\text { o Empathy } \\
\text { - Non-judgmental } \\
\text { - Non-confrontational } \\
\text { o Culturally sensitive }\end{array}$} \\
\hline \multicolumn{3}{|l|}{$\begin{array}{l}\text { Convenient study location centrally located in East } \\
\text { Harlem neighborhood and flexible study visit dates/ } \\
\text { times (included weekends and evenings) }\end{array}$} \\
\hline $\begin{array}{l}\text { Unified communication system } \\
\text { - Google Voice number as single study phone and } \\
\text { texting line } \\
\text { - Single Hunter College email address accessible to } \\
\text { all study staff } \\
\text { - Google calendar as central scheduling platform }\end{array}$ & $\begin{array}{l}\text { - Coordinated monitoring of the } \\
\text { study line and email (especially } \\
\text { with Spanish-speaking participants) }\end{array}$ & $\begin{array}{l}\text { - Additional staff (especially Spanish- } \\
\text { speaking) were added to the study team } \\
\text { - Standardized monitoring/scheduling } \\
\text { procedure incorporated }\end{array}$ \\
\hline $\begin{array}{l}\text { - Thank you cards after third study visit and } \\
\text { reminder for last in-person study visit } \\
\cdot 2 \text { recipes sent between third study and last in- } \\
\text { person study visit }\end{array}$ & & \\
\hline
\end{tabular}

completing study activities impacted retention. However, perceived participant burden is an important aspect of recruitment and retention but there have been few studies that have tried to understand participant burden or benefit. Ulrich et al. found that the higher the perceived burden of the study, the more likely participants are to think about dropping out [23]. Lingler et al. found that participation burden was inversely associated with enrolling in the study and that research burden increased as the study risk categorization 
increased [21]. Bodart et al. found that the length of time and time of day were important factors in perceived burden to complete study questionnaires [22]. Participants in our study reported high satisfaction rates which may indicate that they perceived the study to be low burden. However, participation burden is complex and can be associated with other factors including sociodemographic, level of trust in researchers, and perceived benefit to self or to society.

The selection of gift cards provided to families may have also led to higher retention rates. Formative research was conducted to identify appropriate stores. The large department store retailer was the most popular gift card choice among both parents and children as it had a vast array of items available. It is important to consider the versatility of the incentives provided to participants especially in low resourced areas. Additionally, successful retention strategies included flexible hours, bilingual study staff, incremental monetary incentives, metrocards, and ongoing communication with study participants. Other retention and recruitment research of racial and ethnic minority populations has indicated that these are crucial elements to a successful retention strategy [17, 24-26]. Parents indicated that they felt well informed about the study and felt that study staff answered their questions. We experienced some challenges throughout the study with retention including no-shows and technological challenges experienced by participants such as forgetting passwords/usernames and navigating the intervention tool. Our weekly staff meetings allowed us to identify these challenges early on and implement solutions to maintain high retention rates.

\section{Strengths/limitations of the study}

This study has several limitations that should be taken into consideration. First, our findings are specific to Latino and Black families in East Harlem, NY and may not be generalizable to other ethnic/racial minorities or other geographic locations. Second, families interested in nutrition may more actively seek enrollment into a nutrition study and may be more motivated to complete the study than families that are not interested in nutrition. Third, due to the design of the study, we are unable to determine which retention strategies were most successful. Strengths of this study included detailed documentation of all study protocols, a centralized electronic communication system, and weekly meetings. These factors allowed us to have a clear understanding of protocols that were in place and allowed us to implement solutions based on participant and study staff feedback we reviewed during weekly meetings. The study was also structured to be flexible to make changes to the study protocols in response to challenges encountered throughout the study. Study staff was trained to expect changes and to bring up concerns to team meetings. Study staff also had community outreach and nutrition experience which allowed us to utilize community engagement strategies. In addition, though our findings are limited to only Latino and Black families in East Harlem, we have identified successful strategies for this specific high-risk population and potentially similar others.

\section{Conclusion}

Intervention INC successfully recruited and retained low-income, minority children and their parents in East Harlem. Within our study, the most successful recruitment strategies included community flyering and attending community events. Our high retention rate shows that participation of minority families is possible in longitudinal studies despite a plethora of barriers to lowincome, minority individuals, and potential participant burden. To effectively recruit and retain Latino and Black families into health promotion studies, our results suggest that a variety of strategies-particularly those that build trust and relationships-is necessary. Furthermore, implementing these various types of strategies requires careful planning, detailed tracking, frequent check-ins, and adaptability to modify as needed. More research is needed to determine specifically which recruitment and retention strategies are the most successful among Latino and Black families. This information could create more targeted strategy implementation and subsequent high levels of retention of minority populations in future interventions.

\section{Abbreviations \\ AA: African American; BMl: Body mass index (height $(\mathrm{m}) /$ weight $\left.(\mathrm{kg})^{2}\right)$; C: Control; CBO: Community-based organization; CONSORT: Consolidated Standards for Reporting Trials; E: Experimental; GED: General education development; Intervention INC: Interactive Nutrition Comics for Urban Minority Youth; mHealth: Mobile Health; N: Number; NY: New York; NYC: New York City; SNAP: Supplemental Nutrition Assistance Program; SPSS: Statistical Package for the Social Sciences; T1: Baseline; T2: Intervention midpoint or 3 weeks post-baseline; T3: Intervention end or 6 weeks post- baseline; T4: 3 month follow-up post-intervention; US: Unites States}

\section{Acknowledgements}

The authors want to acknowledge the Children's Aid, our community partners, and the members of our large team for their contribution to this study.

\section{Author' contributions}

MML conceived the study and secured the funding with the support of KFM. GD and SS interpreted the data. LH analyzed the retention and recruitment data. AR and AG assisted with the development of the recruitment and retention protocols. MML, KFM, GD, SS, and LH implemented study protocols and contributed to the writing of the manuscript. All authors read and approved the final manuscript.

\section{Funding}

This study was funded by the Agency for Healthcare Research and Quality (AHRQ) grant \#R21H5024117. The views expressed are those of the authors and not necessarily those of AHRQ. 


\section{Availability of data and materials}

The datasets used and/or analyzed during the current study are available from the corresponding author on reasonable request.

\section{Ethics approval and consent to participate}

All study participants provided written informed consent. The study was approved by Hunter College IRB New York, NY.

\section{Consent for publication}

Not applicable

\section{Competing interests}

The authors declare that they have no competing interests.

\section{Author details}

'Hunter College School of Urban Public Health, City University of New York (CUNY), 2180 Third Avenue, New York, NY 10035, USA. ${ }^{2}$ CUNY Graduate School of Public Health and Health Policy, 55 W 125th Street, New York, NY 10027, USA. ${ }^{3}$ Children's Aid, 711 Third Avenue, Suite 700, New York, NY 10017, USA. ${ }^{4}$ Weill Cornell Medical College, 407 East 61st Street, New York, NY 10065, USA.

Received: 8 April 2019 Accepted: 21 August 2019

Published online: 05 September 2019

\section{References}

1. Taveras EM, Gillman MW, Kleinman KP, Rich-Edwards JW, Rifas-Shiman SL. Reducing racial/ethnic disparities in childhood obesity: the role of early life risk factors. JAMA Pediatr. 2013;167(8):731-8.

2. Joseph G, Dohan D. Recruiting minorities where they receive care: institutional barriers to cancer clinical trials recruitment in a safety-net hospital. Contemp Clin Trials. 2009;30(6):552-9

3. Ford ME, Havstad SL, Davis SD. A randomized trial of recruitment methods for older African American men in the Prostate, Lung, Colorectal and Ovarian (PLCO) cancer screening trial. Clin Trials. 2004:1(4):343-51.

4. Braunstein JB, Sherber NS, Schulman SP, Ding EL, Powe NR. Race, medical researcher distrust, perceived harm, and willingness to participate in cardiovascular prevention trials. Medicine (Baltimore). 2008;87(1):1.

5. Durant RW, Wenzel JA, Scarinci IC, Paterniti DA, Fouad MN, Hurd TC, et al. Perspectives on barriers and facilitators to minority recruitment for clinical trials among cancer center leaders, investigators, research staff and referring clinicians. Cancer. 2014;120(0 7):1097-105.

6. George S, Duran N, Norris K. A systematic review of barriers and facilitators to minority research participation among african americans, latinos, asian americans, and pacific islanders. Am J Public Health. 2013;104(2):e16-31.

7. Wright K, Giger JN, Norris K, Suro Z. Impact of a nurse-directed, coordinated school health program to enhance physical activity behaviors and reduce body mass index among minority children: a parallel-group, randomized control trial. Int J Nurs Stud. 2013;50(6):727-37.

8. Cui Z, Seburg EM, Sherwood NE, Faith MS, Ward DS. Recruitment and retention in obesity prevention and treatment trials targeting minority or low-income children: a review of the clinical trials registration database. Trials. 2015;16 Available from: https://www.ncbi.n/m.nih.gov/pmc/articles/ PMC4674912/.

9. Gul RB, Ali PA. Clinical trials: the challenge of recruitment and retention of participants. J Clin Nurs. 2010;19(1-2):227-33.

10. Pfammatter AF, Mitsos A, Wang S, Hood SH, Spring B. Evaluating and improving recruitment and retention in an mHealth clinical trial: an example of iterating methods during a trial. mHealth. 2017:3 Available from: https://www.ncbi.nlm.nih.gov/pmc/articles/PMC5682361/.

11. Hampl S, Paves $\mathrm{H}$, Laubscher $\mathrm{K}$, Eneli I. Patient engagement and attrition in pediatric obesity clinics and programs: results and recommendations. Pediatrics. 2011;128(Supplement 2):S59-64.

12. Skelton JA, Beech BM. Attrition in paediatric weight management: a review of the literature and new directions. Obes Rev. 2011;12(5):e273-81.

13. Xu F, Marchand S, Corcoran C, DiBiasio H, Clough R, Dyer CS, et al. A community-based nutrition and physical activity intervention for children who are overweight or obese and their caregivers. J Obes. 2017; [cited 2019 Jan 23]. Available from: https:/www.hindawi.com/journals/jobe/2017/2746595/.

14. Leung MM, Mateo KF, Verdaguer S, Wyka K. Testing a web-based interactive comic tool to decrease obesity risk among minority preadolescents: protocol for a pilot randomized control trial. JMIR Res Protoc. 2018;7(11) Available from: https://www.ncbi.nlm.nih.gov/pmc/articles/PMC6251980/.

15. Chen MS, Lara PN, Dang JHT, Paterniti DA, Kelly K. Twenty years post-NIH revitalization act: renewing the case for enhancing minority participation in cancer clinical trials. Cancer. 2014;120(0 7):1091-6.

16. Shavers-Hornaday VL, Lynch CF, Burmeister LF, Torner JC. Why are African Americans under-represented in medical research studies? Impediments to participation. Ethn Health. 1997;2(1-2):31-45.

17. Hartlieb KB. Recruitment strategies and the retention of obese urban racial/ ethnic minority adolescents in clinical trials: the FIT Families Project, Michigan, 2010 - 2014. Prev Chronic Dis. 2015;12 [cited 2019 Jan 15] Available from: https://www.cdc.gov/pcd/issues/2015/14_0409.htm.

18. Carroll JK, Yancey AK, Spring B, Figueroa-Moseley C, Mohr DC, Mustian KM, et al. What are successful recruitment and retention strategies for underserved populations? Examining physical activity interventions in primary care and community settings. Transl Behav Med. 2011;1(2):234-51.

19. Warner ET, Glasgow RE, Emmons KM, Bennett GG, Askew S, Rosner B, et al. Recruitment and retention of participants in a pragmatic randomized intervention trial at three community health clinics: Results and lessons learned. BMC Public Health. 2013;13:192.

20. Heller C, Balls-Berry JE, Nery JD, Erwin PJ, Littleton D, Kim M, et al. Strategies addressing barriers to clinical trial enrollment of underrepresented populations: a systematic review. Contemp Clin Trials. 2014;39(2):169-82.

21. Lingler JH, Schmidt K, Gentry A, Hu L, Terhorst L. Perceived research burden assessment (PeRBA): instrument development and psychometric evaluation. J Empir Res Hum Res Ethics JERHRE. 2014;9(4):46-9.

22. Bodart S, Byrom B, Crescioni M, Eremenco S, Flood E. Perceived burden of completion of patient-reported outcome measures in clinical trials: results of a preliminary study. Ther Innov Regul Sci. 2018; 2168479018788053.

23. Ulrich CM, Zhou QP, Ratcliffe SJ, Knafl K, Wallen GR, Richmond TS, et al. Development and preliminary testing of the perceived benefit and burden scales for cancer clinical trial participation. J Empir Res Hum Res Ethics. 2018:13(3):230-8.

24. Flores $G$, Portillo A, Lin $H$, Walker C, Fierro M, Henry M, et al. A successful approach to minimizing attrition in racial/ethnic minority, low-income populations. Contemp Clin Trials Commun. 2017;5:168-74.

25. Huang $H$, Coker $A D$. Examining issues affecting african american participation in research studies. J Black Stud. 2010;40(4):619-36.

26. Bonevski B, Randell M, Paul C, Chapman K, Twyman L, Bryant J, et al. Reaching the hard-to-reach: a systematic review of strategies for improving health and medical research with socially disadvantaged groups. BMC Med Res Methodol. 2014;14(1):42.

\section{Publisher's Note}

Springer Nature remains neutral with regard to jurisdictional claims in published maps and institutional affiliations.
Ready to submit your research? Choose BMC and benefit from:

- fast, convenient online submission

- thorough peer review by experienced researchers in your field

- rapid publication on acceptance

- support for research data, including large and complex data types

- gold Open Access which fosters wider collaboration and increased citations

- maximum visibility for your research: over $100 \mathrm{M}$ website views per year

At $\mathrm{BMC}$, research is always in progress.

Learn more biomedcentral.com/submission 